\title{
A GAMING APPROACH FOR CULTURAL HERITAGE KNOWLEDGE AND DISSEMINATION
}

\author{
F. Di Paola ${ }^{\text {a*, L. Inzerillo }}{ }^{\text {, }}$, Yuri Alogna ${ }^{\mathrm{a}}$ \\ ${ }^{a}$ DARCH, Department of Architecture, Polytechnic School, 90128 Palermo, Italy \\ francescco.dipaola@unipa.it, laura.inzerillo@unipa.it, yuri.alogna@community.unipa.it
}

\author{
Commission II, WG II/8
}

KEY WORDS: 3D Survey, 3D Modeling, Gamification, Cultural Heritage, VR, AR, Museum

\begin{abstract}
:
In these last years, video games have become one of the most popular entertainment for children/teenagers/adults thanks to their appealing and seductive features and, in this context, the Serious Games (SG) have become an important research field. The most popular SGs in Cultural Heritage $(\mathrm{CH})$ used the historical building like scenario where the game is playing. In this paper we show the procedure to achieve a $\mathrm{CH}$ video game where the Cultural Heritage is the main actor and not the scenario of the game. Furthermore, the game is not a SG but an Action- Adventure Game (AAG) or Survival Game (SuG), in a largest heading it can be classified as Entertainment Games (EGs). The novelty of this study is not only in the original application of the $\mathrm{CH}$ within the AAG sector but also consists of the experimentation of the Virtual Reality (VR) algorithm and of the application of Augmented Reality (AR) within the VR scenario used in the form of an avatar. Furthermore, in this paper we overcome the technical problems due to the different size of the environment and the work art.
\end{abstract}

\section{INTRODUCTION}

Today Virtual Reality is used in numerous fields. In Cultural Heritage it is used to allow anyone to be able to explore an asset in its complexity and wholeness, aimed at monitoring and conservation, at museum set up, at divulgation and dissemination, at overcoming the visual and mobility impairments, at overcoming psychological problems and increasing mental skills, at having a virtual reconstruction of what doesn't exist more, etc. Moreover, now more than in the past it is possible to download VR and AR on mobile devices not only for gaming or $\mathrm{CH}$ dissemination but also to support decision-making in cases such as flood risk management and wind park planning. Recent advances in VR, AR, Artificial Intelligence (AI), and Remote Sensing (RS) have opened up new opportunities for the development of Virtual Experiments (VEs) too (Abt, 1970).

The actual procedures for $\mathrm{CH}$ study and conservation have, as a scientific reference, the data acquisition and their digitalization, aimed at the development of applications for use and knowledge. In this field, the video game industry has contributed in a surprising and attractive way to communicate the $\mathrm{CH}$ with visual and interactive tools, involving the general public. The so-called serious games (SGs) are an effective tool, especially for the new generations, which reflects the technological, socio-economic and historical issues of a subject. Therefore, the videogame is one of the precious essential resources to transmit knowledge and culture. Hence, the gaming environment needs continuous contributions of platforms implementation and technological and procedural development. Nevertheless, the SGs are not so attractive for the last generation that usually play with the Action and Adventure Games. Although SGs have a great communicative value and a great opportunity in terms of learning and training, they have not yet reached a good level of popularity. Contrary to the entertainment market of the AAGs or SuGs, the
SGs market model is not based on a demand/supply ratio, but, instead, on direct funding from organizations interested in the applied game. Hence, the current SGs are mostly created on requests that have as a priority, the educational value, without considering the playability and entertainment of the game, which are the strengths of entertainment games. The challenge is to transform the SGs in AAGs using the $\mathrm{CH}$ environment and tools. For this reason, we have to response the following the European recommendations about the Cultural Heritage and Museum Video Games (Tang, 2018; Thomas, 2018):

- What types of heritage identities, representations, constructions and/or applications are expressed in video games?

- Does heritage representation in video games affect public understandings and world views? How?

- How do video game developers interact with, draw upon or create cultural heritage in their work?

- How are heritage organizations and other institutions engaging with video games in their interactions with the public?

- What is the relationship between video games, cultural heritage and value systems?

- How to develop audience engagement, to create new types of interactions with museum audiences, often far from the ways of telling, living and visiting the museum?

However, on the other hand, it must answer one requirement:

- The CH Game must be brought to as many platforms as possible: PC and Mac, as well as all currentgeneration home video game consoles and mobile devices.

At the same time when you are going to design a CHSG you have to need some choices like the form of fun to provide enjoyment and pleasure, the form of play, the rules, the goals to provide

\footnotetext{
* Corresponding author
} 
motivation, the interactivity to lead to learning by doing, the adaptivity, the outcomes and feedback, the win states to provide ego gratification, the conflicts, competition, challenges and opposition, the problem solving to spark player's creativity, the interaction to promote the socialization, the storytelling and its representation to solicit the emotional sphere.

The present paper discusses video games as an innovative tool for presenting $\mathrm{CH}$ by integrating art, storytelling and digital technology. It focuses on both entertainment games and serious games and provides some illustrative examples of such games whilst discussing their approach and novelty (Bontchev, 2016; André et al, 2014).

The main technological challenges aim at determining new and accessible game engines, new technologies for mixed reality technologies (Virtual and Augmented reality), advanced techniques and tools for graphic rendering (such as realistic control of transparency, reflection and refraction), creating entities commented through tag recognition and artificial intelligence for planning and control of specific dynamics (crowd simulation, NPC behavior - Non Player Character -, content generation and so on).

Whereas video games currently take place in a virtual environment that is played through a $2 \mathrm{D}$ display, games in $\mathrm{AR}$ and Virtual Reality (VR) immerse the users in the game and allow for natural and embodied interactions with the virtual content. Compared to VR, AR games take place in the real world and bring the additional challenge of the game having to adapt to the physical space of the user.

Nevertheless, in our game design, the AR is within the VR environment and it can be accessed through the avatar whether it is in the first person or in the third. The AR implementation plays a fundamental role in the game strategy: thanks to it, the players can find the keys to open the forward level and go on in the power levels. For instance, the avatar will receive the glasses to use the AR only when he reaches level two.

\section{STATE OF THE ART}

Nowadays, there are more than 50 sites for serious/educational games and 10 of them are classified like the serious games that has changed the world. The first serious game has been designed in 1970 and it was built for academic book Serious Game book. Since 1970 until now, more than 100 serious games have been designed and among these only a small part are within Cultural Heritage (Critelli et al, 2012; Francis, 2006; Janarthanan, 2012; Michaud, 2015).

Very interesting examples of this kind are The Battle of Thermopylae (Christopoulos et al., 2011; Laamarti et al, 2014) aiming to deliver the historical context and importance of the battle, the warfare of the opponents, their cultural differences and the strategic choices, and The Siege of Syracuse (Christopoulos et al, 2009) recreating the battlefield of the siege by the romans in 212 BC. Others are The ancient Olympia (Gaitatzes et al., 2004; Syufagi et al, 2013); the Priory Herbert Undercroft, are construction of the Benedictine monastery in Coventry, dissolved by Henry VIII (Doulamis et al., 2011); Revolution (Francis, 2006), a role-playing game in the town of colonial Williamsburg during the American Revolution; The Playing History game series; George Washington's treasures and Rome in Danger. There are also some point-and-click adventures, like TimeMesh, about some significant historic events of Europe (the Second World War, the maritime discoveries in the XV and XVI centuries and the industrial revolution, Signets of Power20recreating the power struggle between the church, the nobility and the Crown in Aarhus, Denmark, depicted in 1458 and the NatGeo Games Lost Chronicles series published by National Geographic (among the episodes: The fall of Julius
Caesar, The mystery of Cleopatra and Salem). Strategy games reenacting famous historical battles are 106622, The Battle of Waterloo23, and The Viking Quest, while simulation games are: Expedition The Game about Stanley's journey to find Dr Livingstone; High Tea (Birchal et al., 2011) set during the opium trade in China; the History Game Canada and Building Detroit. The Cat and the Coupe is a documentary game about the first democratically elected Prime Minister of Iran, Dr Mohammed Mossadegh. This game certainly takes an unusual approach to a genre mainly concerned with depicting reality: the environment is highly abstract and symbolic, and the atmosphere is dreamlike and associative rather than realistic.

\section{METHODOLOGY}

The main aspects which determine the success of a gaming platform are: the structure; the project; the game playability; the realism level and the calculation speed in updating the scenes. In recent years, the Computer Graphic (CG) industry has invested heavily in the design of innovative methods for the efficient creation of game content, using software tools specialized in the automatic production of multi-resolution complex and articulated scenarios. To mention a few, Make3D and Blender 3D, which automatically or semi-automatically convert two-dimensional fixed images into 3D models, allowing a surprising perception of perspective depth. Using a VRML, Flash or Adobe Shockwave viewer, users can "fly" or "walk" through the 3D scene or watch a rendered 3D movie.

So, there are two different challenges that must be faced up and over come: the first one is to transform a SGs in a EGs and the second one is to create a high-level VR of the $\mathrm{CH}$ scenario using and implementing the latest algorithms.

Technically, virtual reality software is based on the "flocking algorithm" In recent years, new algorithms have been developed and executed to improve the efficiency of the results. The goal of VR is to recreate realistic environments by interacting with people or objects in a virtual environment and in real time through the visualization with head-mounted display (HMD) devices.

The software is based on the interaction between artificial life forms, called boids that move in a three-dimensional coordinate system and direction by vector. The motion of the boids can be chaotic or ordered. In the simplest scenario, artificial intelligences decide to modify their trajectories based on three rules: separation (the boid steers in order to avoid local overcrowding, so it moves away from nearby boids); alignment (the boid steers in order to align itself with the flight paths of nearby boids); cohesion (the boid steers itself in order to move towards the middle position of the neighbouring boids. In more complex scenarios): other rules have been introduced, for example to avoid obstacles or achieve objectives (Sun, et al., 2014).

The $i$ th boid's movement in $\mathrm{x}, \mathrm{y}, \mathrm{z}$, Separation (S), can be obtained by (1), in which the coordinate of $i$ th boid is subtracted by the coordinate of its neighbours, $j$ th boid, where $n$ is the number of boids. Actually, we ignore the boids who are far away from $i$ th boid and only concern neighbours surrounding $i$ th boid, hence a distance threshold is needed to define $(x j, y j, z j)$ range.

$\left.S=\left(x_{i}, y_{i}, z_{i}\right)-\left(x_{j}, y_{j}, z_{j}\right)\right) 0 \leq j \leq n, j \neq i$

The $i$ th boid is steered toward the average heading of the local flock mates. Its newest coordinate of the Alignment can be obtained by (2). 


$$
A=\frac{1}{n}\left[\begin{array}{l}
\sum_{j=0}^{n} V_{x j} \\
\sum_{j=0}^{n} V_{y j} \\
\sum_{j=0}^{n} V_{z j}
\end{array}\right]
$$

The $i$ th boid is steered toward the average position of local flock mates (Cohesion). Its coordinate can be obtained by (3). In contrast to the rule of separation, here we ignore those boids nearby $i$ th boid.

$$
C=\frac{1}{n}\left[\begin{array}{l}
\sum_{j=0}^{n} V_{x j} \\
\sum_{j=0}^{n} V_{y j} \\
\sum_{j=0}^{n} V_{z j}
\end{array}\right]-\left[\begin{array}{l}
x_{i} \\
y_{i} \\
z_{i}
\end{array}\right]
$$

This algorithm has been improved (Sung et al., 2018) and in the table below (Tab.1) there are different values before and after the improvement:

\begin{tabular}{|c|c|c|c|}
\hline $\begin{array}{c}\text { Number of } \\
\text { bold (n) }\end{array}$ & $\begin{array}{c}\left(f_{\text {origin }}\right) \text { Frame } \\
\text { per algorithm } \\
\text { (FPS) }\end{array}$ & $\begin{array}{c}\left(f_{\text {improved }}\right) \text { Frame } \\
\text { per algorithm } \\
\text { (FPS) }\end{array}$ & $\begin{array}{c}\text { Frame increase } \\
\text { rate } \\
\varepsilon_{(\%)}\end{array}$ \\
\hline 32 & 1271.7 & 1403.2 & 9.4 \\
64 & 461.4 & 530.0 & 12.9 \\
\hline 128 & 215.4 & 361.9 & 40.5 \\
\hline 150 & 110.5 & 190.1 & 41.5 \\
\hline 160 & 77.5 & 150.5 & 48.5 \\
\hline 170 & 30.6 & 69.8 & 56.2 \\
\hline 180 & 2.9 & 11.3 & 74.3 \\
\hline 256 & 1.4 & 2.3 & 39.1 \\
\hline
\end{tabular}

Tab 1: comparison of the frame performance of two algorithms

$$
\text { frame rate }(\varepsilon)=\frac{f_{\text {improved }}-f_{\text {origin }}}{f_{\text {Improved }}} \times 100(\%)
$$

The case study has been carried out within a museum where the two different paths are addressed into the container in which the contents and the procedures for each one is different. The "flocking algorithm" technique has been implemented within the interface UnReal Engine 4 platform (by Epic Games) with the aim of simulating the randomized movement of museum users during the use of the game.

The following flow charts show the pipeline of the structure of the game design (Fig. 1), the pipeline of the social/cultural/psychological and financial aspects linked to the game design and the pipeline of the technical aspects linked to the creation in VR and AR of the $\mathrm{CH}$ environment. Obviously, the social/cultural/psychological and financial aspects have only been mentioned.

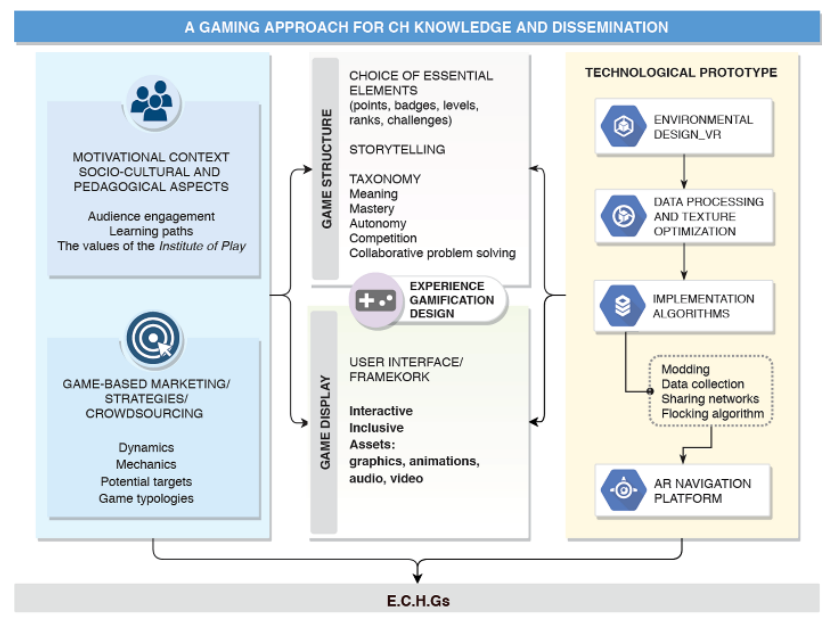

Figure 1. Flow chart of the pipeline of the Entertainment $\mathrm{CH}$ Games design structure

\section{STRATEGIES FOR THE GAMING ENVIRONMENT}

The technologies of Computer Graphics, Web Design and Gaming and the non-invasive 3D digital acquisition techniques with high-performance devices allow to generate applications for the high-resolution visualization of three-dimensional environments with the possibility to navigate, to analyze and to query in real time the virtual models.

The research aims at analysing the actual design strategies of a game structure and to develop procedures to process and to edit 3D data that allow to manage the dedicated platform to the fruition and the knowledge of Cultural Heritage (Di Paola et al., 2017).

The workflow submitted explores and tries to overcome a variety of operative issues that are common in a 3D digital acquisition process of complex objects, such as archaeological artefacts, works of art, decorative or architectural elements. At this point, the applications created, to be placed in an environment with game peculiarities, must have special characteristics, in terms of polygonal weight, quality of texture applied, geometric topology that, obviously, can deeply change in accordance with the kind of digital model created. It highlights the value to develop and manage suitable design, implementation and development strategies for 3D content pipelines in order to visualize cultural photorealistic environment gaming, effectively with today's devices in commerce (Parrinello et al., 2017; Silva, El Saddik, 2013).

For instance, the texture quality is a crucial issue to investigations in the field of Architecture, Civil Engineering, Design, Cultural Heritage, Archaeology and, nowadays, even more than in the past, gaming.

\subsection{The case study. The Regional Archaeological Museum "Antonio Salinas"}

The challenge of this paper is to overcome the technical difficulties due to the presence of objects of different sizes within the video game. For this reason, we have chosen a museum as the environment for SG. The Regional Archaeological Museum "Antonio Salinas" is in Palermo and it has one of the richest and oldest archaeological collections in Italy. The monument is now a testimony to Sicilian history from prehistory to the Middle Ages. Inside are kept finds and artefacts of peoples who determined the history of the Island as Phoenicians, Punic, Greeks, Romans and Byzantines, but also artefacts of other people's such as the Egyptians and Etruscans.

The long construction events that led to the completion of the construction of the House of the Oratorian Monks took place during the long Spanish government of the Island (Inzerillo, 2017).

\section{WORKFLOW AND TOOLS EMPLOYED}

The set pipeline allows you to obtain the architectural scenario furnished with all the elements that characterize it for the creation of a virtual tour in gaming mode that allows the user to immerse himself and navigate the museum environment involving it with a series of infographic information that emphasize the virtual visit. In order to test and evaluate the management and optimization process, it was decided to develop a prototype of a museum setting in game mode, determining the precise design and operational choices described below (type of software in terms of reliability, accuracy and simplicity; software 
implementation tools; export mode; criteria for baking and packing of 3D models, etc.).

The methodological process was carried out in three different phases.
The usual procedure to manage this aspect and reduce the load on the GPU (Graphic Processor), is called "multi-resolution" technique and involves loading, within the game engine, two or more meshes with a different number of polygons.

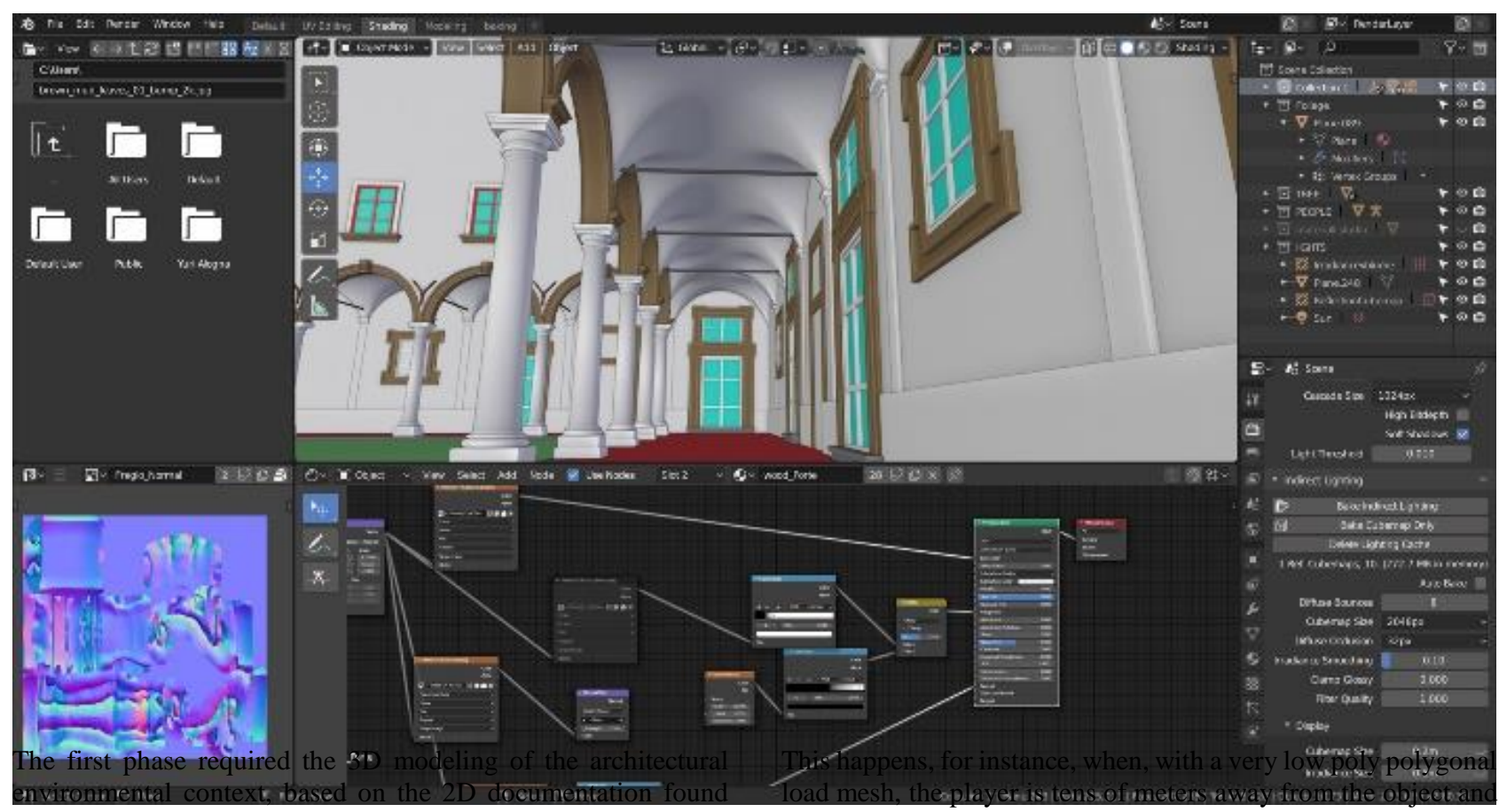

Figure 2. Game environment design using Blender 3D sculpture tools and modifiers

(photographic survey, design drawings, direct survey, planimetric setting).

The second phase involved the digital acquisition with noninvasive photogrammetric techniques of Reverse Modeling of the decorative apparatus and the collections of the museum artefacts. As will be described later, in this step it has been possible to optimize the models acquired with mesh reduction amount and sculpting techniques and the meshes and textures applied to them (Minh et al., 2012; Nguyen et al., 2013; Phothong et al., 2018).

The last phase of "coding" was involved: the coding of the game structure within the UnReal Engine 4 platform (by Epic Games) and the creation of new and specific addons (flocking algorithm) that have made more productive some steps of the workflow editing.

\subsection{Design and optimization techniques}

Returning to the description of the first phase, we describe some of the salient aspects that have characterized the strategic choices adopted.

One of the fundamental concepts for CGI (Computer Graphic Imaging), applied to the world of videogames, is the management of LODs (Level Of Details), which determines the real playability and an effective real-time and interactive display of a game. The acronym establishes, in relation to the position of the player from an object on the scene, the level of detail that is represented of it. The use of appropriate LOD management criteria implies an effective game navigation, correctly exploiting computational resources and hardware performance.

In particular, the hardware component that manages this process is the Video Card, which must generate in real time the context around which the character moves.

Therefore, the level of detail must not and cannot be the same for each object, and for each distance of the player from it. the software loads the next mesh (high poly) to approach the player.

However, as will be described below, for the model with high polygonal load, it is not meant a mesh with the same number of polygons obtained with the photogrammetric techniques used, but these data must be optimized and corrected for subsequent processing.

For the creation of the prototype game presented here, the LOD technique was not used for all the objects on scene, but for some the polygonal load was simply lowered exponentially but using high resolution procedural textures.

This procedural choice has allowed to satisfy the requirement to contain the final weight of the whole project to visualize and to interact with the models also through devices with more limited hardware resources.

The whole architectural structure has been modelled, textured and rendered within the Blender work environment (stable version 2.79 and beta version 2.8). The latter is a cross-platform open source software, distributed under the GPL license. One of the strengths of this software is the presence of modifiers, in other words, specific non-destructive effects parametrically applicable to a mesh, such as subdivision or deformation. The modifiers most used for the creation of the three-dimensional scene have been: Subdivision Surface, Bevel Modifier, Smooth Mesh, and Mirror Modifier (Fig. 2).

\subsection{Sculpting and mesh reduction amount}

With this aim, the processes of Retopology and Remeshing (software used: MeshLab and Instant Meshes) on polygonal models have been started. These two processes replace a mesh with a new one that reflects certain characteristics. The rebuilt mesh with a reduced number of polygonal faces (low poly) is required to conform to two fundamental requirements: it must 
maintain the shape of the original mesh (high poly) and it must have a topology which conforms to the aims of the project.

However, when the geometry is organic, many details are lost during the Retopology phase, but they are also displayed using procedural textures, during the phase called Baking. These procedural textures are specially created to store information in 2D maps without adding geometry to the model, such as the Displacement map, the Lightmap, the Cavity map, etc. (Fig. 3). Usually the texture on the 3D model is often worse than that of 2D images mainly because: the individual texture on the 3D model comes from different image sources; there are many camera and environmental parameters or, the logistical problems due to data acquisition (under/over-exposed areas, low ambient lighting) (Minh et al., 2012; Remondino, 2003).

These aspects could produce several issues that give us a result that doesn't correspond to the real object with regards to the geometry and the texture mapping (Chen et al., 2012; Finlay et al., 2012; Goldluecke, Cremers, 2009).

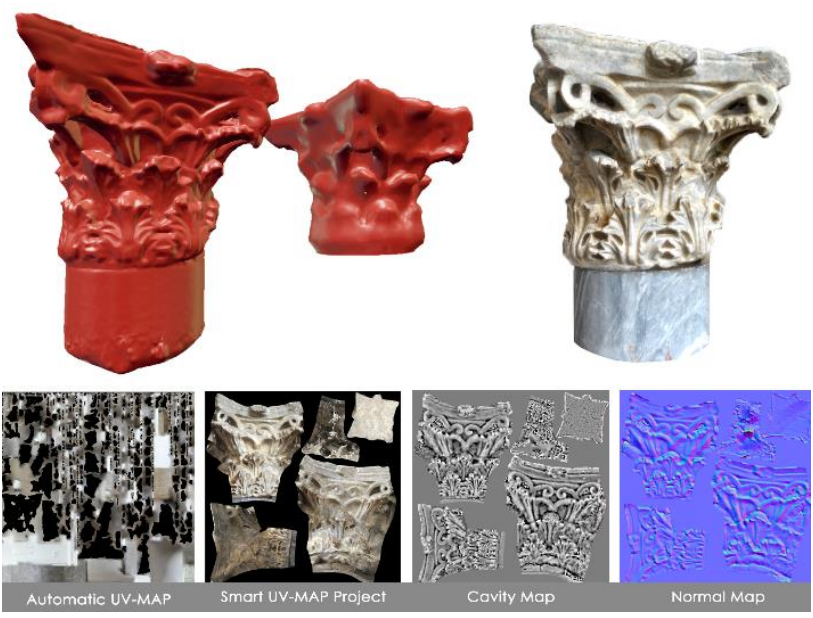

Figure 3. The Retopology phase on an architectural element and the Baking one by procedural 2D maps

The textures, which reproduce the scene's cladding materials, have been reproduced in procedural mode, using the node editor available within Blender. The various procedural maps used were subsequently combined with each other through mixing tools, following specific logics.

The nodes are basically constituted of three types of sockets:

- "Colour node" (in yellow), colour information is transferred with RGB channel values (not including the Alpha channel).

- "Numerical" (in grey), numerical information is displayed, in the format of a floating variable, using sliders that go from 0 to 1. The values are converted to grayscale (e.g. Alpha Channel, Ambient Occlusion).

- "Vector" (in blue), coordinate information is displayed, in general, vector type information (e.g., Roughness Amount).

- "Shader node" (in green), contain information about the internal operation, recognition and conversion within the Blender Rendering Cycles engine of the previous nodes connected to it (for example, Principled BSDF node) (Fig. 4).

\section{CONCLUSIONS}

Some games for fun will continue stay open for modifications with means of adapting and evolving the original game, which creates opportunities for adding didactical and cultural elements to them like SGs (Bontchev, 2016). Nonlinear and interactive storytelling applied games for cultural heritage will increasingly be used for immersive cultural presentation, learning, evaluation and training. In the big world scenario, our research is well correlated and overcome some problems that, until now, have been reduced the application and dissemination of SG games.
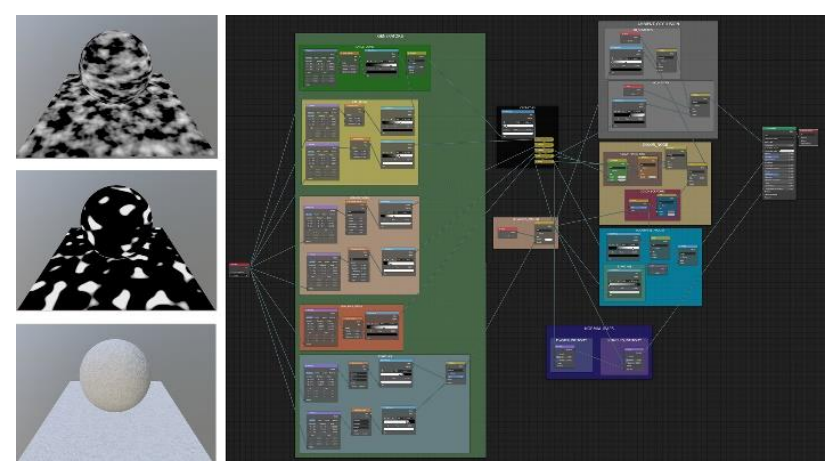

Figure 4. The procedural texture creation which reproduce the scene's cladding materials within the Blender node editor

By employing the proposed workflow there is great potential in producing high resolution textures associated to models with different resolutions (high poly/low poly) in relation to the final use (conservation or real-time $3 \mathrm{D}$ visualization and gamification).

Some advanced surface segmentation methods were used to reconstruct the texture, used in the Blender environment. Alternative methods were also proposed, defined by implementing an algorithm, written in Python. These alternative developed methods create a mesh unwrap that is more compatible with the geometric-formal features of a complex photorealistic environment and with other custom user-defined semantic criteria (Figs. 5-7).

The results present design and optimization techniques and strategies for the gaming environment.

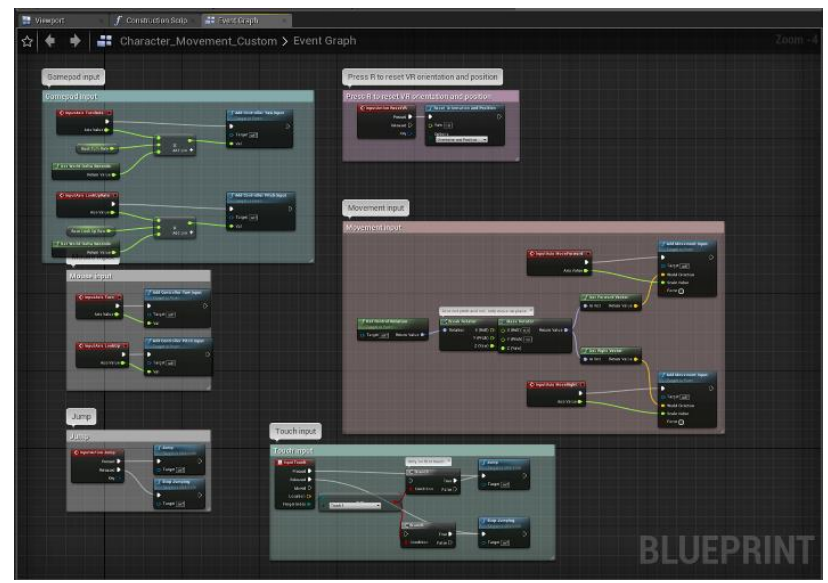

Figure 5. Setting the Unreal Engine 4 Blueprint Visual Scripting node interface 


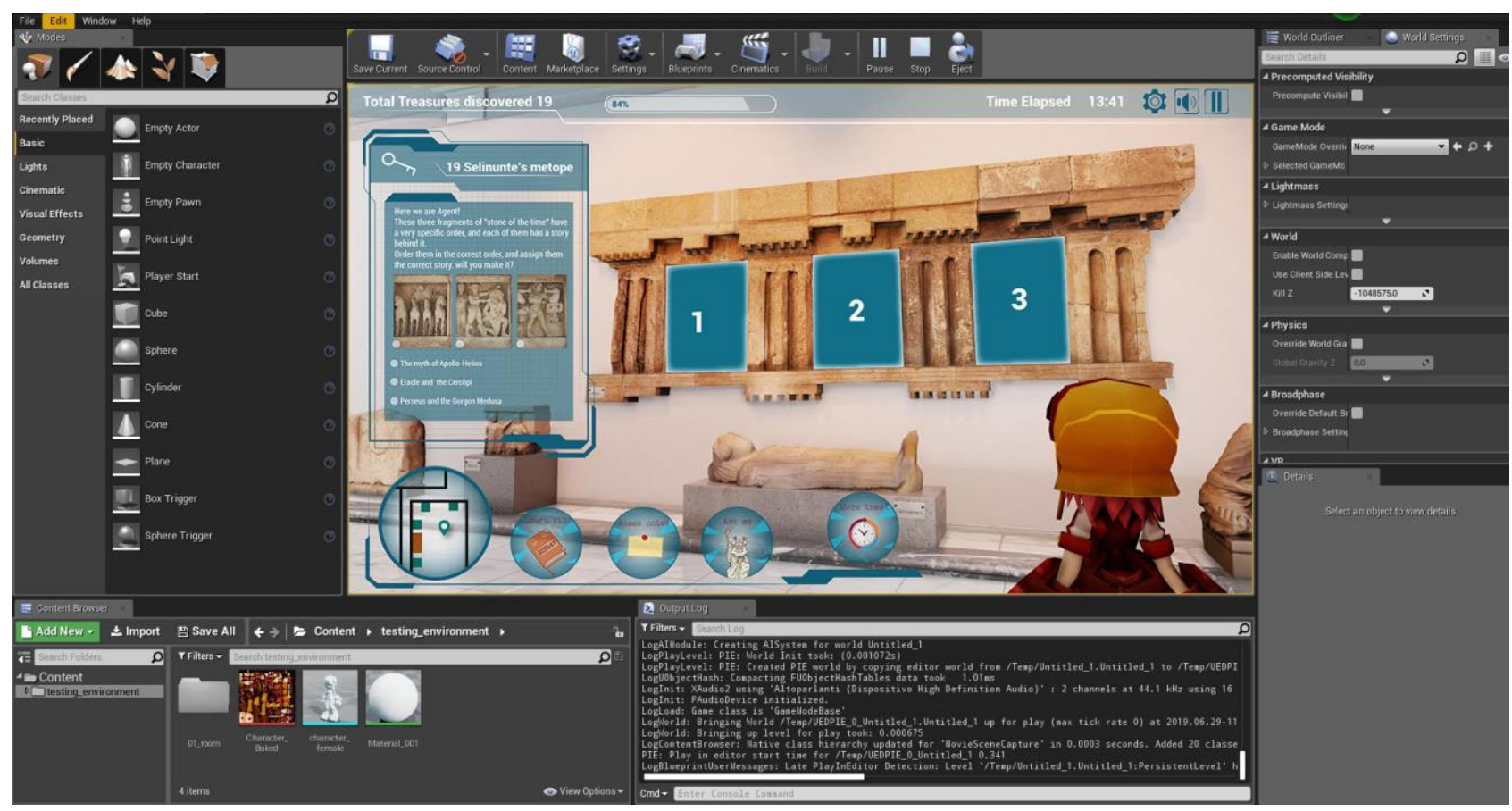

Figure 6. Game environment and play modality for young target audience. Configuration of the context and of the player's paths within the UnReal Engine 4 platform. Design of the selection and interaction modalities of the contents within the UnReal Engine 4 platform.

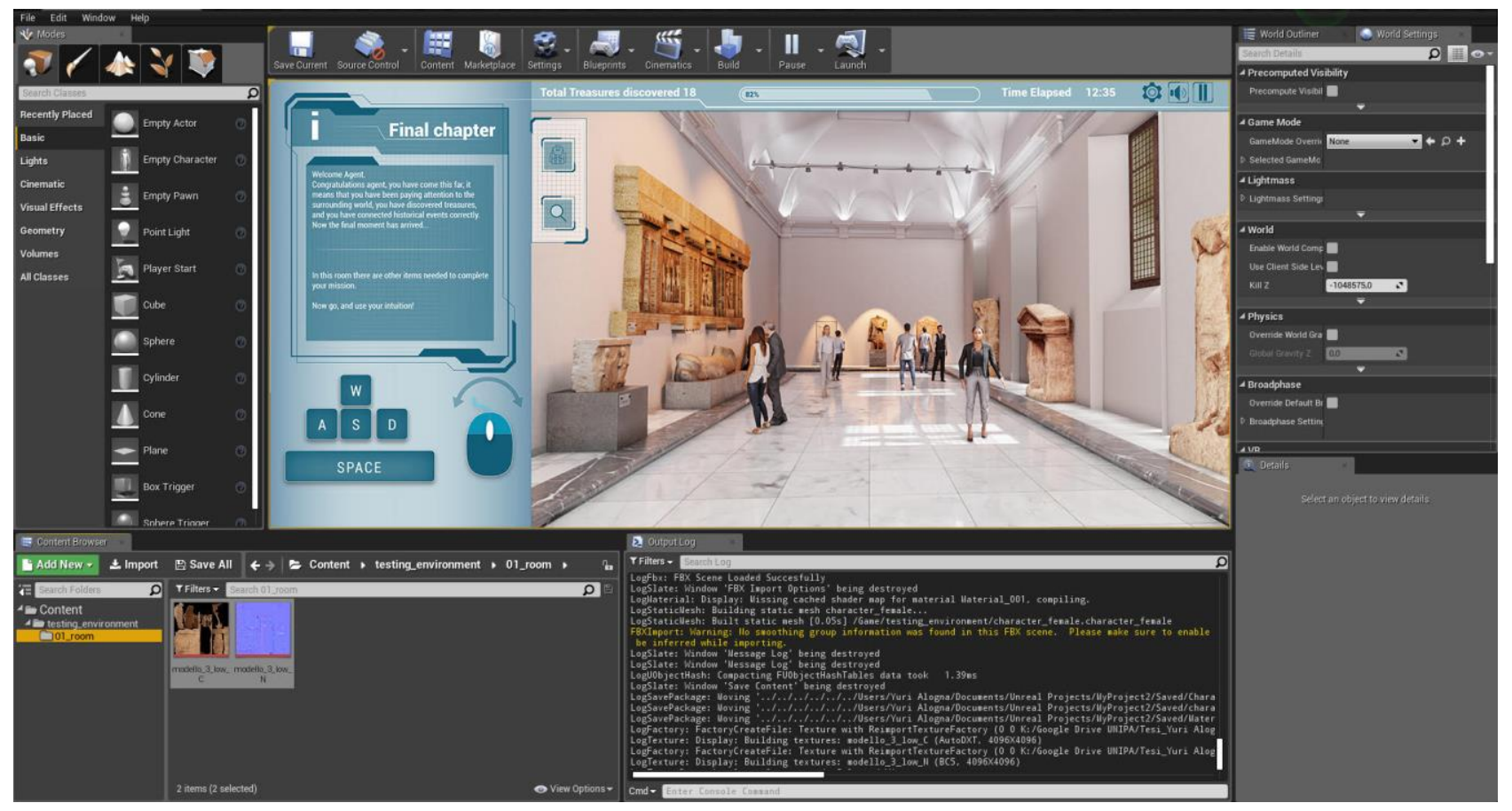

Figure 7. Game environment and play modality for adult target audience. Configuration of the context and of the player's paths within the UnReal Engine 4 platform. Design of the selection and interaction modalities of the contents within the UnReal Engine 4 platform. 


\section{ACKNOWLEDGEMENTS}

This research has received funding from the European Union's Horizon 2020 Programme, SMARTI ETN, under the Marie Curie-Skłodowska actions for research, technological development and demonstration, under grant agreement number 721493.

The authors are really thankful to the Head of the Archaeological Museum, Dr. Francesca Spatafora, the web designer Dr. Sandro Garrubbo and the archaeologist Dr. Elena Pezzini and all the employees of the Salinas Museum.

\section{REFERENCES}

Abt, C. C., 1970. Serious Games. New York: Viking. American Behavioral Scientist, L.C. 79-83234, 14(1), 176.

André, F. S., Barbosa Pedro, N. M., João, A. F. F. Dias \& Frutuoso, G. M. Silva, 2014. A new methodology of design and development of serious games. International Journal of Computer Games Technology, 8.

Birchall, D., Henson, M., 2011. High Tea Evaluation Report, Welcome Trust,

http://museumgames.pbworks.com/w/file/fetch/44614076/ [last access 28/06/2019]

Bontchev, B., 2016.

https://www.slideshare.net/BoyanBontchev/serious-games-forand-as-cultural-heritage-plenary-lecture [last access 28/06/2019]

Chen, Z., Zhou, J., Chen, Y., \& Wang, G., 2012. 3D texture mapping in multi-view reconstruction. Advances in Visual Computing, v. 7431 of Lecture Notes in Computer Science, 359371. Springer Berlin Heidelberg.

Critelli, M., Schwartz, D. I., \& Gold, S., 2012. Serious social games: designing a business simulation game. Proceedings of the 4th IEEE 2012 International Games Innovation Conference, IGiC.

Christopoulos, D., Mavridis, P., Andreadis, A., Karigiannis, J.N., 2011. Using virtual envi-ronments to tell the story: The battle of Thermopylae. Proceedings of VS-Games.

Christopoulos, D., Gaitatzes, A., 2009. Multimodal interfaces for educational virtual environments, informatics, 2009. PCI '09. 13th Panhellenic Conference, 197-201.

Di Paola, F., Milazzo, G. \& Spatafora, F., 2017. Computer aided restoration tools to assist the conservation of an ancient sculpture. the colossal Statue of Zeus enthroned. International Archives of the Photogrammetry, Remote Sensing and Spatial Information Sciences - ISPRS Archives, CIPA, XLII XLII 2/W5, 177-184, Copernicus Publ.

Doulamis, A., Liarokapis, F., Petridis, P., Miaoulis, G., 2011. Serious games for cultural applications. D. Plemenos, G. Miaoulis (Eds.), Artificial Intelligence Techniques for Computer Graphics, Springer.

Gaitatzes, A., Christopoulos, D., Papaioannou, G., 2004. The Ancient Olympic Games: Being Part of the Experience. Proceedings of the 5th International Sym-posium on Virtual Reality, Archaeology and Intelligent Cultural Heritage VAST 110.
Goldluecke, B., \& Cremers, D., 2009. Super resolution texture maps for Multiview reconstruction. Proceedings of the 12th International Conference on Computer Vision, ICCV, 16771684.

Finlay, J., Wilson, A., Milburn, K., Nguyen, M. H., Lutteroth, C., \& Wünsche B. C., 2012. An investigation into graph cut parameter optimisation for image-fusion applications. Proceedings of Image and Vision Computing New Zealand, IVCNZ, 480-485, Dunedin, New Zealand.

Francis, R., 2006. Revolution, learning about history through situated role play in a virtual environment, in: Proc. of the American educational research association conference.

Inzerillo, L., 2017. Smart SfM: Salinas archaeological museum. International Archives of the Photogrammetry, Remote Sensing and Spatial Information Sciences - ISPRS Archives 42 2W5, 369373.

Janarthanan, V., 2012. Serious video games: games for education and health. Proceedings of the 9th International Conference on Information Technology, ITNG, 875-878.

Laamarti, F., Mohamad, E. \& El Saddik A., 2014. An Overview of Serious Games. International Journal of Computer Games Technology, ID 358152, 15.

Michaud, L., 2015. Serious Games, A 10 billion euro market in 2015. IDATE Consulting \& Research.

Minh, H.N., Burkhard, C.W., Delmas, P., \& Lutteroth, C., 2013. A hybrid image-based modelling algorithm. Proceeding of the 36th Australasian Computer Science Conference, ACSC, 115123, Adelaide, Australia.

Minh, H.N., Burkhard, C.W., Delmas P., \& Lutteroth, C., 2012. 3D models from the black box: investigating the current state of image-based modeling. Communication Proceedings, WSCG, 249-258, Pilsen, Czech Republic.

Nguyen, H.M., Wünsche, B., \& Delmas, P., 2013. HighDefinition Texture Reconstruction for 3D Image-based Modeling. 21 st International Conference on Computer Graphics, Visualization and Computer Vision.

Parrinello, S., Bercigli, M., \& Bursich, D., 2017. From survey to $3 \mathrm{D}$ model and from $3 \mathrm{~d}$ model to "videogame". The virtual reconstruction of a Roman Camp in Masada, Israel. DISEGNARECON-Archaeological drawing, 10(19), 1-19.

Phothong, W., Wu, T. C., Lai, J. Y., Yu, C. Y., Wang, D. W., \& Liao, C. Y., 2018. Quality improvement of 3D models reconstructed from silhouettes of multiple images. ComputerAided Design and Applications Journal, 15.

Remondino, F., 2003. From Point Cloud to Surface, the modeling and visualization problem. International Archives of the Photogrammetry, Remote Sensing and Spatial Information Sciences, Vol. XXXIV-5/W10.

Silva, J. M., \& El Saddik, A., 2013. Exertion interfaces for computer videogames using smartphones as input controllers. Multimedia Systems, vol. 19, n. 3, 289-302.

Syufagi, M. A., Hariadi, M., \& Purnomo, M. H., 2013. Petri net model for serious games based on motivation behavior 
The International Archives of the Photogrammetry, Remote Sensing and Spatial Information Sciences, Volume XLII-2/W15, 2019 27th CIPA International Symposium "Documenting the past for a better future”, 1-5 September 2019, Ávila, Spain

classification. International Journal of Computer Games Technology, ID 851287, 12.

Tang, J., 2018. http://www.digra.org/cfp-video-games-andcultural-heritage/ [last access 28/06/2019]

Thomas, S., 2018. https://blogs.helsinki.fi/dig-tool-devmuseum-durgapuja/2018/12/11/call-for-papers-special-issue-onvideo-games-and-cultural-heritage/ [last access 28/06/2019] 